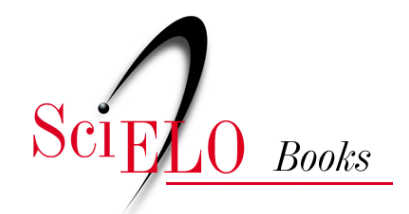

\title{
Considerações finais ou notas sobre uma situação eloquente
}

\author{
Silvia Aguião
}

\section{SciELO Books / SciELO Livros / SciELO Libros}

SILVA, A. Considerações finais ou notas sobre uma situação eloquente. In: Fazer-se no "Estado": uma etnografia sobre o processo de constituição dos "LGBT" como sujeitos de direitos no Brasil contemporâneo [online]. Rio de Janeiro: EdUERJ, 2018, pp. 301-307. Sexualidade, gênero e sociedade. Sexualidades e cultura collection. ISBN 978-85-7511-489-6.

https://doi.org/10.7476/9788575115152.0012.

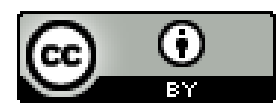

All the contents of this work, except where otherwise noted, is licensed under a Creative Commons Attribution 4.0 International license.

Todo o conteúdo deste trabalho, exceto quando houver ressalva, é publicado sob a licença Creative Commons Atribição 4.0.

Todo el contenido de esta obra, excepto donde se indique lo contrario, está bajo licencia de la licencia $\underline{\text { Creative Commons }}$ Reconocimento 4.0. 


\section{CONSIDERAÇÕES FINAIS OU NOTAS SOBRE UMA SITUAÇÃO ELOQUENTE}

Como visto no primeiro capítulo, as conferências estaduais, além de discutirem propostas locais, têm como um de seus objetivos a eleição dos delegados que representam o estado na conferência nacional. Para tal, a metodologia é a seguinte: os participantes da reunião podem se inscrever em duas categorias: como delegados, que têm voz e voto em plenária e podem ser eleitos como representantes para a etapa nacional; ou observadores, que podem até ter voz, mas nunca voto durante a reunião. Os delegados, por sua vez, são subdivididos em "poder público" ou "sociedade civil", conforme a sua inserção institucional. Na plenária final, por meio de chapas compostas pelos credenciados como delegados, são eleitos aqueles que irão assumir a representação na próxima etapa da conferência.

Até então, em todas as conferências das quais eu já havia participado, o meu crachá sempre foi de observadora. Mas nesse evento não foi assim. Durante a pré-conferência realizada na capital, cumprindo uma das etapas que antecederam a reunião estadual, minha posição no campo foi alterada. Nesse nível do processo das conferências, todos os presentes estão aptos a se reunirem em chapas para disputar uma vaga como delegação, ou não. 
Eu e outras pessoas ligadas ao Laboratório da UERJ estávamos participando da conferência e contribuindo em diferentes grupos de trabalho, mas não estávamos particularmente interessados em nos credenciar como delegados para a próxima etapa, a conferência estadual, pois estávamos certos de que poderíamos estar presentes e contribuir da mesma forma, continuando no nosso papel de observadores. No entanto, no momento de composição das chapas, fomos persuadidos a nos credenciar como "poder público", uma vez que todos tínhamos vínculo, como professores ou estudantes, com universidades públicas. Além disso, estávamos colaborando para a implantação de uma política pública no governo do estado.

Naquela pré-conferência, o número de vagas disponíveis para delegados era grande e foi montada uma chapa única reunindo "poder público" e "sociedade civil", logo, não haveria qualquer disputa. Todos os dispostos nas chapas seriam automaticamente eleitos delegados, bastando, para tanto, que a plenária referendasse a chapa montada.

Nós, da Universidade, discutimos um pouco sobre se aquele era o nosso lugar, "o poder público". Não era assim que nos enxergávamos a princípio. Se tivéssemos que escolher lados, provavelmente o primeiro impulso seria o de nos colocarmos ao lado da "sociedade civil". Mas acabamos por admitir que os argumentos eram convincentes. Mesmo que esse não fosse o lugar mais confortável para o pesquisador, era o que éramos instados a assumir naquele contexto. Entendemos que os gestores do governo, que seriam os demais integrantes da chapa, compreendiam que o apoio da Universidade era importante e, afinal, estávamos de fato envolvidos em um trabalho de parceria estreita com o governo do estado para a implantação de parte da política Rio Sem Homofobia.

Assim, dois meses depois, ao chegarmos à II Conferência Estadual LGBT do Rio de Janeiro, eu e os outros pesquisadores ligados à Universidade recebemos o crachá de "poder público". Não nos preocupamos mais com isso durante a conferência, até que percebemos que havia chegado o momento de formação das chapas para a eleição de delegados para a etapa nacional da reunião. E essa discussão começou a aparecer pelos corredores. 
A essa altura já sabíamos que, além da nossa situação, havia um entendimento geral naquela conferência de que as universidades ali presentes (UERJ e UFRJ), por serem órgãos públicos, e outras entidades como a OAB, ou Conselhos regionais e federais de psicologia ou serviço social estavam sendo entendidos como "poder público", portanto, pessoas vinculadas a essas instituições receberam o respectivo crachá, diferentemente de outros eventos, nos quais pesquisadores ou professores de universidades públicas receberam o crachá de observadores ou convidados. ${ }^{1}$

O fato é que se formaram duas chapas de "poder público", uma composta por pessoas inseridas na instância de governo com a qual a UERJ trabalhava em parceria (entendidos como "os da situação") e outra de pessoas não ligadas ao governo do estado e com alguns posicionamentos bastante críticos em relação às ações levadas a cabo por essa gestão (entendidos como "de oposição"). E, então, as duas chapas nos abordaram com um convite para composição e ficamos, nós, os "pesquisadores da academia" (nesse momento, subsumida como "A UERJ”), numa "saia justíssima”. Localizados nessa situação como "poder público", éramos pressionados a nos posicionar de um lado ou de outro. Não queríamos compor nenhuma das duas chapas, mas o que significava politicamente uma recusa ou uma aceitação para qualquer um dos lados, ou mesmo o que significava ficar "em cima do muro" e não assumir nenhum dos lados?

Considero essa uma situação eloquente, na medida em que oferece uma miríade de leituras possíveis. Entretanto, irei aqui abordá-la brevemente, retomando as principais questóes situadas nas três partes que estruturam este livro.

A primeira delas pode ser pensada acerca da delegação e da representação. O que significava nessa conjuntura a Universidade representar o "poder público"? Por que isso nos causava estranheza? Como essa delegação nos comprometia?

1 Ou em outras situaçōes, como, por exemplo, o Conselho Estadual LGBT do Rio de Janeiro, no qual os pesquisadores que na conferência estavam definidos como "poder público" ocupavam a vaga de "sociedade civil". 
Essa situação fala sobre o traçado artificial de determinadas fronteiras ou da justaposição de domínios tidos como idealmente distintos - inclusive por nós mesmos, muitas vezes, "os acadêmicos". E, nessa cena, a nossa resistência diante do crachá de "poder público" é sintomática, uma vez que a distinção entre nós e eles torna-se borrada. Porém, a situação fala também sobre um processo de conversão ou "colonização" a que estão sujeitos pesquisadores coagidos a se engajarem e a se comprometerem política e moralmente com os seus objetos de estudo. A ação de "comprometer-se" envolvida nessa circunstância aponta para os dois sentidos que podem ser atribuídos à palavra: "obrigar por compromisso", "responsabilizar" e "expor (alguém ou a si próprio) a situação constrangedora ou perigosa", "empenhar ou arriscar (palavra, honra, patrimônio etc.)". ${ }^{2}$ Essa situação nos forçou a sair da trincheira de qualquer fantasia remanescente de neutralidade que eventualmente ainda pudesse existir e nos obrigou a assumir os riscos de um determinado posicionamento no campo político, riscos estes já previstos desde muito antes daquele acontecimento.

A segunda questão a ser retomada versa sobre o que essa situação nos diz a respeito dos conflitos e das disputas que envolvem esses "sujeitos em processo". A "academia" surge como um ator de peso nessa cena não apenas por conta dos significados que produz ou (re)afirma por meio de pesquisas, mas também por ser ator ativo no fazer das políticas e nas "respostas do Estado". A situação explicita a inclusão desses atores também no que muitas vezes é considerado um campo de disputas internas dos seus objetos de estudo. Outro ângulo a ser considerado, diretamente relacionado a este, é a "academia" ou o "saber acadêmicocientífico" como um marcador social da diferença, que, como qualquer outro marcador, pode atribuir qualidades positivas ou negativas aos sujeitos que constitui, a depender de relaçôes e contextos contingentes.

E a terceira questão, que agora pode parecer bastante óbvia, é que a "academia" é parte dos processos que compõem a nossa imaginação de "Estado". Não apenas porque está atrelada a uma instituição pública, mas também porque os seus modos de funcionamento e a legitimidade

${ }^{2}$ Verbete "Comprometer". Dicionário Caldas Aulete. 
atribuída à sua "produção científica" também constroem os modelos ideais a partir dos quais produzimos essa imaginação.

Divisôes entre academia, ativismo ou movimento social, governo ou estado falam sobre disputas de território e espaço no campo, sobre competiçôes por financiamentos, sobre a produção e o deslocamento de hierarquias, entre outras coisas. O que importa não é definir o que essas categorias significam exatamente, mas compreender como elas são mutuamente produzidas e de que maneira são manejadas em cada contexto. Ao começar esta pesquisa, eu tinha o palpite de que deveria olhar para essas três arenas: a produção acadêmica sobre gênero e sexualidade, as movimentações do ativismo "LGBT" e as políticas levadas a cabo no plano governamental. De fato, elas apareceram com força no campo da pesquisa, e eu pude continuar operando com elas. Mas, meu próprio posicionamento e papel no campo, intencionalmente ou não, mostrou-me como essas arenas, entendidas como categorias de reflexão, são facilmente desmontáveis ou idealizadas. Pode-se atribuir tais deslocamentos, por sua vez, tanto às estratégias desenvolvidas no interior da arena política para colocar o pesquisador em determinada posição quanto a táticas assumidas por este no sentido de aceitar a posição na qual foi colocado ou buscar definir-se como pertencente a um ou a outro lugar.

No que foi dito até aqui, é perceptível que os significados de "campo" se misturam: o campo político (como aquele tratado por Bourdieu) e o campo da pesquisa (de que fala o jargão antropológico). Creio que essa oscilação de sentido reflete a dimensão colocada entre participar da produção de um campo político ao mesmo tempo que se produz o campo tomado como um objeto de pesquisa. Ou, nesse caso, colaborar para a implantação de uma política pública do governo do estado, que resulta de imediato na produção justamente do campo que se toma como objeto de estudo.

A relação entre movimento social, governo e academia, como acompanhada ao longo da pesquisa, ecoa o conceito de "tríade" elaborado por George Simmel (1950). Ainda que não se enquadre exatamente na tipologia traçada pelo autor, podemos considerar a relação entre os elementos segundo o seu modelo de tríade sociológica, 
pois carrega os traços de uma relação imanente/persistente entre os elementos. As configurações que operam entre a tríade excluem a possibilidade de um absoluto contraste entre os seus elementos, ainda que, ocasionalmente, uma parte seja contrastada à outra e que alianças permanentes ou temporárias estejam sempre sendo formadas.

Souza Lima e Castro (2008) apostam na superação da separação entre mundos de "ONGS" e "universidades", "militantes" e "pesquisadores" que foram construídos como separados, em grande parte como um aspecto do "efeito de Estado" presente em nossa percepção da vida social, sobretudo quando lidamos com e de dentro da administração pública:

Ao invés de um conjunto de estereótipos sobre o seu fazer profissional, a atitude do antropólogo em trabalhos 'aplicados' deve ser a de um humilde 'profissional do estranhamento', atento à permanente reinvenção de assimetrias, que exercerá uma atitude dialógica, seja no interior da administração pública, seja debatendo com uma comunidade [...] Cremos que ai está o plano inicial para a ponte entre mundos separados e para um assenhoreamento de nosso papel quando atuamos 'fazendo Estado', seja como produtores de conhecimento el ou ideologias, seja no exercício executivo de processos de intervenção: criar os mecanismos para mudar da mera sensação de estar 'implicado' numa situação para a consciência de que, de um modo ou de outro, nunca estamos fora do campo da produção para o 'aplicado' (p. 378).

Pensando novamente no modelo da tríade desenvolvido por George Simmel, é a própria relação que sustenta o equilíbrio entre os elementos engajados na interação, ainda que seja um equilíbrio instável.

Sustentar o processo de reconhecimento pelo "Estado" requer manter o equilíbrio das tensóes que ocorrem nas fímbrias dessa trama de relações. As contradições e as instabilidades mencionadas, por sua vez, devem ser pensadas como inerentes a tal formação política. O que torna "sujeitos LGBT" possíveis como uma "população" a ser administrada é o fato de conseguirem se produzir fazendo sentido no interior de uma determinada morfologia de estado como população 
“imaginável”, modelável e adaptável dentro de uma gramática, cujas regras e limites são mais ou menos elásticos.

Nos limites deste livro procurei dar conta de algumas das dimensões desse processo, e elas certamente não foram esgotadas aqui. Outros caminhos para o aprofundamento dessas dimensões são possíveis e necessários para a compreensão das dinâmicas políticas que permitem a produção e a articulação entre sujeitos, formatos de administração governamental e a constituição de direitos. 